Article

\title{
An Investigation of Different Text Levels on L2 Learners' Vocabulary Learning Rates in an Extensive Reading Program
}

\author{
Anna C-S Chang \\ Hsing-Wu University \\ doi: http://dx.doi.org/10.7820/vli.v04.1.chang
}

\begin{abstract}
This study investigated whether different text levels would affect L2 learners' vocabulary learning rates and further examined the correlation between the frequency of word occurrence and learning rates in two different task conditions. A group of 31 year-11 senior high-school students read five level 1 graded readers, a total of 28,796 words, and then moved on to read five level 3 graded readers, 54,676 words, during a 13 -week period. One hundred and twenty-five target words were selected from the 10 graded readers, 51 words from level 1, and 74 from level 2 texts. A vocabulary test containing two test methods was administered to students: a 125-item form-meaning matching test and a 42 item contextualized translation test. Twenty-one low-frequency words from each level text were selected to examine the frequency of word occurrence and learning rates. The meaning matching test results demonstrated that the learning rate at level 1 was significantly higher than those of level 3 in the post-test. The attrition rate of level 1 texts was also higher, which led to no significant difference in learning rates in the delayed post-test. A similar learning pattern can be said for the contextualized translation tests. Positive but statistically insignificant correlations between the frequencies of occurrence of 21 target words were found in the post-tests but were stronger in the delayed post-test in both meaning matching and translation tests. Overall, the learning rates for both level 1 and level 3 texts were very high. Four reasons for the higher learning rates were explained. Pedagogical implications are discussed.
\end{abstract}

\section{Background}

\subsection{Learning Vocabulary through Extensive Reading}

The benefits of reading have been well documented in both L1 and L2 learning, one of them being gaining vocabulary knowledge. Relatively low learning rates were reported by many previous studies that examined the extent of words incidentally learned through reading a single passage or a book (e.g., Day, Omura, \& Hiramatsu, 1991; Dupuy \& Krashen, 1993; Horst, Cobb, \& Meara, 1998; Pellicer-Sánchez \& Schmitt, 2010). Learning rates, however, were found much higher through extensive reading. For example, Cho and Krashen (1994) found that the vocabulary learning gains of four L2 adults who read 8-23

Please cite this article as: Chang, A.C-S (2015). A Japanese word association database of English. Vocabulary Learning and Instruction, 4 (1), 47-57. doi: 10.7820/vli.v04.1.chang 
books over four months ranged from $56 \%$ to $80 \%$ of tested vocabulary. Horst's (2005) study with 17 ESL learners who read over a six-week period showed that the acquisition rate for the 1,001-2,000 level words was $76 \%$ and $62 \%$ the off-list words, with an average of $69 \%$. In an in-depth case study of one French language learner who read four graded readers over one month and was tested with 133 words, Pigada and Schmitt (2006) found 66 words (50\%) were improved in one type of word knowledge, $13(10 \%)$ in two types, and $8(6 \%)$ in three types, with a pick-up rate of $65 \%$. Learners of different prior knowledge before reading were found to have a different learning rate. In their two-term study with 60 Taiwanese students, Webb and Chang (2015b) found that students' learning rates were $63.18 \%, 44.64 \%$, and $28.12 \%$ for the high-, intermediate-, and low-level students, respectively, and the rates were quite comparable within each group during the two-term period. A few reasons may account for the higher word learning rates through extensive reading. The first one is that unknown or partially known words may be repeatedly encountered in the texts, and the more they read, the more opportunities they have to encounter the same words (Webb \& Chang, 2015 b). Second, in reading multiple books, it is not possible to prevent learners from using dictionaries to look up unknown words or to ask peers or teachers the meanings of unknown words. This course of action increases the attention for involvement and observation, which, in turn, may result in higher learning rates. Third, the more one reads, the better that person's reading skills become and in turn leads to higher comprehension level and higher word learning rates (Nation \& Wang, 1999). These above reasons have made extensive reading a valuable source for developing L2 vocabulary knowledge.

Despite these extensive reading studies having demonstrated impressive learning gains, the quantity in this line of research is still very limited because most studies have focused on general vocabulary knowledge improvement. Thus, more research into this area is needed to provide more empirical evidence. Moreover, the first three studies mentioned above looked at the effectiveness of L2 learners reading self-selected books on vocabulary learning gains, which limited our understanding of whether text levels had connection to the learning gains. This issue seems to have been partly solved by more recent research by Webb and Chang (2015b) who examined EFL learners studying two levels of texts (level 1 and level 2); and students' learning gains were found quite similar between level 1 and level 2. Theoretically, reading an easier text should enable a student to acquire more words than reading a more difficult one because easier texts tend to lead to higher level of comprehension, so readers could give more attention to unknown words (Pulido, 2004). To provide further evidence in this area, this study intended to compare whether a group of students who read easier texts (level 1) would gain more than they would by reading more difficult texts (level 3).

A few studies have examined the correlation between learning the formmeaning connection and the number of times each word occurred in reading a single text, and a moderate correlation has been found. For example, Saragi, Nation, and Meister (1978) found a correlation of .34 and Vidal (2011) identified a correlation of .47. Horst et al. (1998) reported a correlation of .49. Webb (2007) found a correlation of .43 for recall meaning and .23 for recognition of meaning. Not until very recently, though, had studies ever examined the effects of repetition 
in multiple texts. Webb and Chang (2015a) examined how frequency and distribution of occurrence affect learning rates with 61 Taiwanese students who studied 10 level 1 books. The correlation between relative gain [(the number of words gained from learning/unknown words) $\times 100]$ in the post-test and the frequency of occurrence was found to be negatively low and non-significant ( $r=-.03, p=.78, n=100)$. A possible reason could be that mixed levels of target words were randomly selected from the 10 different graded readers. This study, therefore, would further explore the correlations between these two variables but focus on low-frequency words only. To evaluate more accurately learners' receptive and productive knowledge, two test methods were used: the form-meaning matching test and the contextualized translation test. Two research questions are addressed:

RQ1: To what extent would different text levels affect L2 learners' vocabulary learning rates from reading graded readers?

RQ 2: What were the correlations between frequency of word occurrence and relative gains in different text levels and in different test methods?

\section{The Study}

\subsection{The Participants}

A group of 42 year-11 senior high-school students took part in the extensive reading program; however, only 31 of them consistently attended the program throughout. These students had engaged in extensive reading for a year before the intervention started. Their vocabulary knowledge assessed through the bilingual Vocabulary Levels Test (Schmitt, Schmitt, \& Clapham, 2001) were 26/30 and 22/30 for the first and second 1,000 words. ${ }^{1}$

\subsection{The Study Materials}

Five level 1 and five level 3 graded readers were selected from the Bookworm series and the Macmillan series (see Appendix A for the details). The total word count of the level 1 text was 28,796 and 54,676 for level 3 texts. The lexical profile of the two level texts is shown as below.

Table 1. Lexical Profile of Level 1 and Level 3 Graded Readers

\begin{tabular}{lrrrc}
\hline \multicolumn{5}{c}{ Tokens (\%) } \\
\hline Word list & Level 1 & $\begin{array}{c}\text { Cumulative } \\
\text { coverage }+ \text { proper } \\
\text { nouns }\end{array}$ & Level 3 & $\begin{array}{c}\text { Cumulative } \\
\text { coverage }+ \text { proper } \\
\text { nouns }\end{array}$ \\
\hline 1,000 & $24,778(86.05 \%)$ & $90.92 \%$ & $46,926(85.83 \%)$ & $89.49 \%$ \\
2,000 & $1,616(5.61 \%)$ & $96.53 \%$ & $3,108(5.61 \%)$ & $95.17 \%$ \\
$\begin{array}{l}\text { Proper } \\
\text { nouns }\end{array}$ & $1,402(4.87 \%)$ & & $2,010(3.68 \%)$ & \\
Total & 28,796 & & 54,676 & \\
\hline
\end{tabular}

Vocabulary Learning and Instruction, 4 (1), 47-57. 


\subsection{The Target Words and Dependent Measures}

A total of 125 target words were selected to be tested, among which 51 words were from the level 1 texts and 74 words from the level 3 texts. The target words were analyzed with GSL range (Nation \& Heatley, 2002) and Nation's (2012) BNC/COCA range. Approximately, 35\% of the target words from level 1 texts and 55\% from level 3 texts were in the lists of words beyond the 3,000 level.

The target words were measured through two test methods: a form-meaning matching test and a contextualized translation test. The former contained 125 target words divided into 10 blocks. Each block had 8-15 target words. The order of the items was rearranged in the immediate post-tests and the delayed post-tests. An example from a pretest is shown as below.

\begin{tabular}{|c|c|}
\hline 1.__ armour & a. 正義 \\
\hline 2.__ judge & b. 請願 \\
\hline 3.___ justice & c. 法律 \\
\hline 4.__ petition & d. 盔甲 \\
\hline 5.___ gang & e. 法官 \\
\hline 6.___ creek & f. 獎賞 \\
\hline _outlaw & g. 子彈 \\
\hline _ bullet & h. 幫派 \\
\hline 9.___ reward & i. 多徒 \\
\hline & j. 小溪 \\
\hline
\end{tabular}

Figure 1. Form-Meaning Matching Test Example.

The contextualized translation tests involved 42 low-frequency words (21 from each text level) that were selected from the 125 target words. An example taken from Christmas in Prague is given below. The students had to translate the underlined word into Chinese.

Carol is never late for rehearsals, and she knows that these concerts are important for us. (演練).

The correlations between frequency of word occurrence and learning rates: The frequency of the 21 off-list words from each text level was examined, and then the learning gains in the two test methods were computed. The frequency of the 42 words is shown in Appendix B. 


\subsection{Procedure}

The two forms of vocabulary pretests were administered to the participants before the intervention. The translation test was taken first, then the form-meaning matching test. After the pretest, the students read one level 1 text each week, followed by an immediate post-test at week 6 , and a three-month delayed post-test at week 17. The same procedure was repeated after students had read the level 3 texts. The test procedure is presented below. The level 3 texts were longer than those of level 1 , so it took the participants eight weeks to finish reading the five readers.

\begin{tabular}{lll}
\hline 1st week & Pretest & 51 level 1 words \\
6 th week & Post-test & 51 level 1 words \\
6 th week & Pretest & 74 level 3 words \\
14 th week & Post-test & 74 level 3 words \\
17 th week & Delayed post-test & 51 level 1 words \\
25 th week & Delayed post-test & 74 level 3 words \\
\hline
\end{tabular}

Figure 2. Test Procedure.

To ensure that all participants did read the texts, all reading was completed in their weekly three-hour reading class. Before students started to read, the instructor usually introduced the story or the author's background. While students were reading, they also listened to the oral rendition of texts. The instructor would stop the audio CD from time to time to check students' comprehension or to allow students to ask questions. After finishing a story, the students could take notes, ask questions, or discuss the story with their classmates. All the after-reading activities were voluntary and allowed students to have some time to think about what was read, to check up unknown words in the dictionary, or to write personal feelings about the story. Before the students returned each book, a simple comprehension quiz was given.

\section{Results}

Table 2 shows that before the treatment, the participants were familiar with approximately a half of the target words in the level 1 texts and slightly more than one third in level 3 in the form-meaning matching test. In the contextualized translation test (see Table 3), the participants also knew about a half of the level

Table 2. Descriptive Statistics of Form-meaning Matching Test across Three Occasions

\begin{tabular}{llcccc}
\hline Text & & Mean & \multicolumn{1}{c}{ SD } & Minimum & Maximum \\
\hline Level 1 (51 words) & Pretest & $25.94(51 \%)$ & 6.20 & 13 & 39 \\
& Post-test & $47.68(93 \%)$ & 5.03 & 28 & 51 \\
& Delayed post-test & $45.39(89 \%)$ & 5.64 & 31 & 51 \\
Level 3 (74 words) & Pretest & $27.55(37 \%)$ & 9.91 & 10 & 47 \\
& Post-test & $65.48(87 \%)$ & 10.07 & 38 & 75 \\
& Delayed post-test & $62.19(83 \%)$ & 10.44 & 40 & 75 \\
\hline
\end{tabular}

Vocabulary Learning and Instruction, 4 (1), 47-57. 
Table 3. Descriptive Statistics of Contextualized Translation Test across Three Occasions

\begin{tabular}{llcrrr}
\hline & & Mean & SD & Minimum & Maximum \\
\hline Level 1 (21 words) & Pretest & $10.35(49 \%)$ & 3.98 & 3 & 18 \\
& Post-test & $20.16(96 \%)$ & 1.29 & 17 & 21 \\
& Delayed post-test & $18.90(90 \%)$ & 3.03 & 9 & 21 \\
Level 3 (21 words) & Pretest & $1.81(9 \%)$ & 1.60 & 0 & 6 \\
& Post-test & $18.13(86 \%)$ & 2.67 & 13 & 21 \\
& Delayed post-test & $17.03(81 \%)$ & 3.61 & 10 & 21 \\
\hline
\end{tabular}

Table 4. Descriptive Statistics for Different Text Levels and Learning Rates in the Form-meaning Matching Tests and Translation Tests $(n=31)$

\begin{tabular}{|c|c|c|c|c|}
\hline \multicolumn{3}{|c|}{ Level 1} & \multicolumn{2}{|c|}{ Level 2} \\
\hline & Relativegain1 & Relativegain2 & Relativegain1 & Relativegain2 \\
\hline \multicolumn{5}{|c|}{ Form-meaning matching tests } \\
\hline Mean & $87.07(18.75)$ & $76.74(24.42)$ & $79.33(21.47)$ & $71.43(26.66)$ \\
\hline Min-max & 17.86 to 100 & 0 to 100 & 28.85 to 100 & -14.29 to 100 \\
\hline \multicolumn{5}{|c|}{ Translation tests } \\
\hline Mean & $93.22(10.37)$ & 81.92 (21.69) & $85.51(13.30)$ & $79.82(18.10)$ \\
\hline Min-max & $71.43-100$ & $33.33-100$ & $60-100$ & $44.43-100$ \\
\hline
\end{tabular}

1 target words; however, they knew only 9\% of the words for the level 3 texts $(1.81 / 21)$. This meant that the participants would have many more words to learn from level 3 texts than from the level 1 texts.

RQ1: To what degree would different text levels affect L2 learners' vocabulary learning rates from reading graded readers?

The relative gains presented in Table 4. The results of form-meaning matching test show that the relative gains were very high for both level 1 and level 3 texts. There was a significant difference in relative gain 1 between level 1 texts and level 3 texts, $t(30)=2.67, p=.012$; however, the effect size calculated with Cohen's $d$ was small $(d=0.38)$. The relative gain 1 for the level 1 text $(M=87.03)$ was significantly higher than that of level 3 texts $(M=79.33)$. No significant difference was found in relative gain 2 between level 1 and level 3 texts, which suggested that the attrition of level 1 words learned was higher than that of level 3 (see Table 5).

Similar results can be said for the contextualized translation tests. There was a statistically significant difference in relative gain $1, t(30)=3.15, p=.004$, and the effect size was medium (Cohen's $d=0.65$ ). No marked difference was found in relative gain $2, t(30)=.49, p=.63$ (see Table 5 ). These above results provide answers to the first research question. 
RQ 2: What were the correlations between frequency of word occurrence and gains in different text levels and in different test methods?

In the form-meaning matching tests, the correlations between frequency of word occurrence and relative gain in the level 1 texts were found to be positive but insignificant $(r=.04, p=.88$ ) The same results can be said for the level 3 texts $(r=.11, p=.65)$; however, the correlations seem to be stronger in the delayed post-test than in the immediate post-test in the both level $1(r=.15, p=.51)$ and level 3 texts $(r=.24, p=.30$; see Table 6$)$.

In the contextualized translation tests, the correlations were positive in both level $1(r=.16, p=.49)$ and level $3(r=.22, p=.35)$ texts and in both the immediate post-test and the delayed post-test. The correlations were found to be comparable for the level 1 texts $(r=.20, p=.38)$ than for the level 3 texts $(r=18$, $p=.45)$. The answer to the second research question was that there were positive but statistically insignificant correlations between frequency of word occurrence

Table 5. Paired-Sample $t$-Tests for Relative Gains of Vocabulary Learning Rates between Level 1 and Level 3 Texts on the Meaning Matching and Translation Tests

\begin{tabular}{|c|c|c|c|c|c|c|c|c|}
\hline & Mean & SD & SEM & $95 \%$ CID & $t$ & df & $p$ & $\begin{array}{l}\text { Effect size } \\
\text { (Cohen's } d \text { ) }\end{array}$ \\
\hline \multicolumn{9}{|c|}{ Form-meaning matching tests } \\
\hline $\begin{array}{c}\text { Relative } \\
\text { gain } 1\end{array}$ & 7.74 & 16.16 & 2.90 & 1.81 to 13.67 & 2.67 & 30 & .012 & 0.38 \\
\hline $\begin{array}{r}\text { Relative } \\
\text { gain } 2\end{array}$ & 5.31 & 25.98 & 4.67 & -4.23 to 14.83 & 1.14 & 30 & .27 & 0.21 \\
\hline \multicolumn{9}{|c|}{ Translation tests } \\
\hline $\begin{array}{c}\text { Relative } \\
\text { gain } 1\end{array}$ & 7.70 & 13.61 & 2.44 & 2.71 to 12.70 & 3.15 & 30 & .004 & 0.65 \\
\hline $\begin{array}{r}\text { Relative } \\
\text { gain } 2\end{array}$ & 2.10 & 23.84 & 4.28 & -6.64 to 10.85 & .49 & 30 & .63 & 0.11 \\
\hline
\end{tabular}

Note: Relative gain 1: From the pretest to the post-test; relative gain 2: From the pretest to the delayed post-test.

Table 6. Correlations between Frequency of Word Occurrence and Gains in Different Test Methods and Different Text Levels

\begin{tabular}{lccc}
\hline Test methods & Text level & Relative gain 1 & Relative gain 2 \\
\hline Form-meaning matching & 1 & .04 & .16 \\
& 3 & .11 & .23 \\
Contextualized translation & 1 & .16 & .20 \\
& 3 & .22 & .18 \\
\hline
\end{tabular}

Note: Relative gain 1: From the pretest to the post-test; relative gain 2: From the pretest to the delayed post-test.

and relative gains. The correlations were slightly stronger in the delayed post-tests in the form-meaning matching tests but were mixed in the contextualized translation tests for different level texts. 


\section{Discussion and Conclusion}

The learning gains of the present study were slightly higher than those of previous studies. Four factors may explain the results: reading amount, motivation, comprehension check, and fondness for the selected stories. As to the amount of reading, these 31 students had been reading for a year before this study began. Their reading skills, therefore, might be competent and could be accustomed to reading immediately after the intervention. Second, most of the students were highly motivated learners. They took notes on what they learned from the graded readers although the instructor did not require them to do so. The third reason might be the comprehension check activity after reading. As per the students' request, the instructor took one of the after-reading activities from the worksheets provided by the publishers, the one most often used being putting the events in order. This comprehension check activity might have caused students to read more carefully and comprehend more. According to Stoeckel, Reagan, and Hann (2012), students who took simple quizzes felt slightly greater intellectual benefit from the reading task. Finally, in the students' interview reports, all reported that words learned from stories were easily remembered, and the better they liked a story, the more words they learned and the longer they retained the words. That these stories had been read by previous students and rated as very interesting could be one very important factor explaining the high learning gains.

To the correlations between the frequency of word occurrence and relative gains, the present study did not demonstrate significant correlations in different text levels nor did it in test methods. The main reason could be that exposure frequency is only one of many factors affecting the extent of word knowledge being learned from reading. Other factors, such as word context, elaboration of word processing, or types of word knowledge being assessed, may all come into play and influence the word frequency needed to learn knowledge of a word.

The present study consistently showed that the relative gains were statistically significant only in the immediate post-test. The results have an important implication on learning vocabulary through reading. Learning gains start to decay immediately after learning. Whatever level texts are studied or test methods are used would make no difference to learning gains after a three-month period. This suggests that learners need to continue reading so as to have opportunities for repeated exposure. This supports some scholars' suggestion that reading intervals between texts should be short. Nation and Wang (1999) suggest that learners should read at least one graded reader per week, and Prowse (2002) suggests more than one per week. How L2 learners acquire word knowledge from extensive reading is still under-researched. Future research in this area is certainly warranted.

\section{Note}

1. The 1st 1,000 word level was developed by Professor Paul Nation of Victoria University of Wellington, New Zealand. 


\section{References}

Cho, K.-S., \& Krashen, S. D. (1994). Acquisition of vocabulary from the Sweet Valley Kids series: Adult ESL acquisition. Journal of Reading, 37, 662-667.

Day, R. R., Omura, C., \& Hiramatsu, M. (1991). Incidental EFL vocabulary learning and reading. Reading in a Foreign Language, 7, 541-551. http://nflrc. hawaii.edu/rfl/PastIssues/rfl72day

Dupuy, B., \& Krashen, S. D. (1993). Incidental vocabulary acquisition in French as a foreign language. Applied Language Learning, 4, 55-63.

Horst, M. (2005). Learning L2 vocabulary through extensive reading: A measurement study. Canadian Modern Language Review, 61, 355-382. doi:10. 3138/cmlr.61.3.355

Horst, M., Cobb, T., \& Meara, P. (1998). Beyond A Clockwork Orange: Acquiring second language vocabulary through reading. Reading in a Foreign Language, 11, 207-223. http://nflrc.hawaii.edu/rfl/PastIssues/rfl112horst

Nation, I. S. P. (2012). The BNC/COCA word family lists. Unpublished manuscript. Retrieved from http://www.victoria.ac.nz/lals/about/staff/paulnation

Nation, I. S. P., \& Heatley, A. (2002). Range: A program for the analysis of vocabulary in texts [software]. Retrieved from http://www.victoria.ac.nz/lals/ staff/paul-nation/nation.aspx

Nation, I. S. P., \& Wang, K. M.-T. (1999). Graded readers and vocabulary. Reading in a Foreign Language, 12, 355-380. http://nflrc.hawaii.edu/rfl/PastIssues/ rfl122nation

Pellicer-Sánchez, A., \& Schmitt, N. (2010). Incidental vocabulary acquisition from an authentic novel: Do Things Fall Apart? Reading in a Foreign Language, 22, 31-55. http://nflrc.hawaii.edu/rfl/April2010/articles/pellicersanchez

Pigada, M., \& Schmitt, N. (2006). Vocabulary acquisition from extensive reading: A case study. Reading in a Foreign Language, 18(1), 1-28. http://nflrc.hawaii. edu/rfl/April2006/pigada/pigada

Prowse, P. (2002). Top ten principles for teaching extensive reading: A response. Reading in Foreign Language Journal, 14(2), 142-145. http://nflrc.hawaii.edu/ rfl/October2002/discussion/prowse

Pulido, D. (2004). The relationship between text comprehension and second language incidental vocabulary acquisition: A matter of topic familiarity? Language Learning, 54, 469-523. doi:10.1111/j.0023-8333.2004.00263.x

Saragi, T., Nation, I. S. P., \& Meister, G. F. (1978). Vocabulary learning and reading. System, 6(2), 72-78. doi:10.1016/0346-251X(78)90027-1

Schmitt, N., Schmitt, D., \& Clapham, C. (2001). Developing and exploring the behaviours of two new versions of the Vocabulary Levels Test. Language Testing, 18, 55-88. doi:10.1177/026553220101800103

Stoeckel, T., Reagan, N., \& Hann, F. (2012). Extensive reading quizzes and reading attitudes. TESOL Quarterly, 46, 187-198. doi:10.1002/tesq.10 
Vidal, K. (2011). A comparison of the effects of reading and listening on incidental vocabulary acquisition. Language Learning, 61, 219-258. doi:10.1111/j.14679922.2010.00593.x

Webb, S. (2007). The effects of repetition on vocabulary knowledge. Applied Linguistics, 28(1), 46-65. doi:10.1093/applin/am1048

Webb, S., \& Chang, C.-S. (2015a). Second language vocabulary learning through extensive reading with audio support: How do frequency and distribution of occurrence affect learning? Language Teaching Research. Advance online publication. doi:10.1177/1362168814559800

Webb, S., \& Chang, C.-S. (2015b). How does prior word knowledge affect vocabulary learning progress in an extensive reading program? SSLA. Advance online publication. doi:10.1017/S0272263114000606 


\section{Appendix A: Study Materials and Word Count}

\begin{tabular}{lc}
\hline Text level & Word count \\
\hline Level 1 & \\
The President's Murderer & 5,270 \\
White Death & 6,600 \\
Ned Kelly & 5,775 \\
Sherlock Holmes and Duke's Son & 5,800 \\
Christmas in Prague & 4,720 \\
Level 3 & \\
Chemical Secret & 10,149 \\
The Call of the Wild & 11,045 \\
The Hound of the Baskervilles & 8,878 \\
The Woman in Black & 11,003 \\
The Picture of Dorian Gray & 12,975 \\
\hline
\end{tabular}

\section{Appendix B: 42 Low-Frequency Words and Their Frequency of Occurrence}

\begin{tabular}{llrlr}
\hline & $\begin{array}{c}\text { Five level 1 } \\
\text { books }\end{array}$ & Frequency & $\begin{array}{l}\text { Five level 3 } \\
\text { books }\end{array}$ & Frequency \\
\hline 1 & ambulance & 3 & certificate & 7 \\
2 & armour & 8 & biologist & 8 \\
3 & bullet & 7 & growl & 9 \\
4 & gang & 35 & marsh & 68 \\
5 & courtroom & 12 & mist & 23 \\
6 & drug & 16 & downstream & 7 \\
7 & duchess & 7 & portrait & 26 \\
8 & guardhouse & 1 & seal (n) & 24 \\
9 & heroin & 44 & sewage & 5 \\
10 & hostage & 12 & solicitor & 8 \\
11 & innocent & 5 & torch & 9 \\
12 & jury & 19 & wrinkle & 10 \\
13 & kidnapper & 3 & journalist & 4 \\
14 & orchestra & 7 & gallery & 8 \\
15 & outlaw & 11 & chemist & 5 \\
16 & rehearsal & 4 & corridor & 2 \\
17 & twin & 2 & hound & 14 \\
18 & tyre & 13 & telescope & 8 \\
19 & conductor & 8 & moose & 6 \\
20 & harpist & 6 & gravestone & 7 \\
21 & petition & 3 & cement & 3 \\
\hline
\end{tabular}

